\title{
Regional logistics demand forecasting: a BP neural network approach
}

\author{
Lijuan Huang $^{1} \cdot$ Guojie Xie $^{1}$ (1) $\cdot$ Wende $\mathrm{Zhao}^{2} \cdot$ Yan Gu$^{1} \cdot$ Yi Huang $^{1}$
}

Received: 5 December 2020 / Accepted: 6 February 2021

(c) The Author(s) 2021

\begin{abstract}
With the rapid development of e-commerce, the backlog of distribution orders, insufficient logistics capacity and other issues are becoming more and more serious. It is very significant for e-commerce platforms and logistics enterprises to clarify the demand of logistics. To meet this need, a forecasting indicator system of Guangdong logistics demand was constructed from the perspective of e-commerce. The GM $(1,1)$ model and Back Propagation (BP) neural network model were used to simulate and forecast the logistics demand of Guangdong province from 2000 to 2019. The results show that the Guangdong logistics demand forecasting indicator system has good applicability. Compared with the GM $(1,1)$ model, the BP neural network model has smaller prediction error and more stable prediction results. Based on the results of the study, it is the recommendation of the authors that e-commerce platforms and logistics enterprises should pay attention to the prediction of regional logistics demand, choose scientific forecasting methods, and encourage the implementation of new distribution modes.
\end{abstract}

Keywords E-commerce $\cdot$ Logistics demand $\cdot \operatorname{GM}(1,1)$ model $\cdot$ BP neural network model

\section{Introduction}

Since the birth of the first vertical business to business (b2b) commercial website "ChinaChemNet" in the 1990s, China has gradually entered a new economic era characterized by the development of e-commerce [1, 2]. E-commerce plays an important role in creating consumer and investment demand, opening up employment channels, stimulating innovative activities, and driving regional economic development [3, 4]. Due to the continuous improvement of upstream, midstream and downstream industrial supply chains, the development

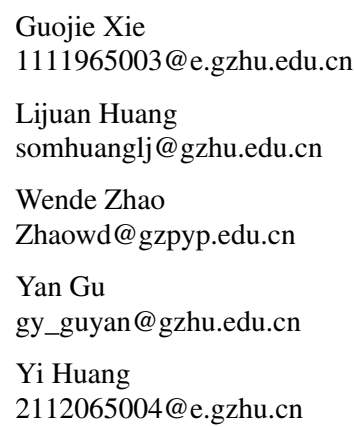

1 School of Management, Guangzhou University, Guangzhou, China

2 School of Management, Guangzhou Panyu Polytechnic, Guangzhou, China of e-commerce is gradually accelerating [5]. Meanwhile, there have been great changes in closely related logistics. For example, Inoue et al. [6] showed that an ecosystem strategy based on the e-commerce market can significantly improve the performance of logistics companies. However, some scholars (e.g. Hsiao et al. [7]; Kim et al. [8]) believe that based on the perspective of consumers, logistics systems can only play its role by integrating the whole e-commerce supply chain.

Relevant data indicate that the development of e-commerce has boosted the demand for regional logistics. According to data released by the China Federation of Logistics and Purchasing (2019), the transaction scale of China's e-commerce market reached 28.4 trillion yuan in 2018 [9]. The rapid development of e-commerce has brought about a huge demand for logistics transportation and distribution. In 2018, China's courier industry's same-city business volume totaled 11.41 billion pieces, which is an increase of $23.1 \%$ yearon-year. In addition, off-site business volume totaled 38.19 billion pieces, which is an increase of $27.5 \%$ year-on-year. Also, international/Hong Kong, Macao and Taiwan business volume totaled 1.11 billion pieces, up 34\% year-on-year [9]. In the national total express, e-commerce delivery accounts for a very high proportion reaching over $60 \%$. In the business of major private courier companies, e-commerce orders account for more than $80 \%$ [9]. 
However, the rapid development of e-commerce also poses the following new requirements and challenges for logistics and distribution:

1. Last-mile delivery to e-commerce customers has always been one of the biggest challenges for logistics providers. The last-mile product delivery is also an expensive option for retailers [10]

2. Logistics and distribution providers are often unable to meet the delivery needs of customers during peak e-commerce shopping periods [11]. Due to the rapid development of e-commerce and the wide areas covered by e-commerce networks, logistics providers are unable to meet the demand for logistics and distribution. This is because their logistics and distribution capabilities lag behind the development speed of e-commerce [12]. Much of the reason for such problems lies in the uneven development speed between e-commerce on the one hand and logistics on the other hand.

Recently, some scholars, based on different perspectives, have conducted relevant studies on the problem of insufficient logistics distribution capacity. For example, Mladenow et al. [13] and Huang et al. [14] propose that the introduction of crowdsourcing logistics will effectively address the last mile of urban logistics distribution, as well as mitigate peak periods problems such as inadequate logistics and distribution capacity. Ishfaq and Sox [15], Hsiao and Hansen [16], Hsu and Wang [17], Yu et al. [18], and others use different forecasting models to forecast regional logistics demand to provide decision support for local economic development. However, in the era of e-commerce, the impact of e-commerce on logistics and distribution cannot be ignored. Also, the indicators related to the development of e-commerce need to be taken into account when making regional logistics forecasts. Therefore, based on the literature review, an indicator system for forecasting logistics demand in Guangdong province was constructed, and applied the GM $(1,1)$ model and the BP neural network model to simulate and forecast the logistics demand. After comparing the two methods, the BP neural network model with less prediction error and more stable results was chosen to forecast the logistics demand of Guangdong province for 2020-2022. The contributions of this paper are:

1. The indicator system for logistics demand forecasting, based on e-commerce perspective, can better reflect the actual scale of logistics demand.

2. By comparing the two methods, it is found that BP neural network has the least error in the prediction of logistics demand and has a good application prospect.
The remainder of the paper is arranged as follows: the second part presents the literature review. The third part describes the research methodology. The fourth part is data analysis and regional logistics demand forecasting. The fifth part discusses the theoretical and practical contributions of this paper. Finally, the sixth part presents the conclusion, limitations and the further work that need to be carried out.

\section{Literature review}

\section{The impact of e-commerce on logistics}

In a discussion of the relationship between e-commerce and logistics, Delfmann et al. [19] and He et al. [20] earlier proposed that logistics is an important part of e-commerce, which guarantees the realization of e-commerce and the smooth progress of production. In other words, logistics serves e-commerce. However, with the rapid development of e-commerce, the relationship between e-commerce and logistics is also changing.

During the early stages of e-commerce development, Sink and Langley [21] believed that the market was mainly dominated by third-party logistics companies and self-run logistics companies. In this stage, the logistics company mainly serves the enterprise that has the distribution demand. With the rapid development of e-commerce and the further enhancement of its influence, logistics alliance mode [22] and crowdsourcing logistics mode appear [13, 14]. Logistics alliance mode refers to long-term cooperation in the form of a contract between two or more enterprises or organizations to achieve certain logistics goals [22]. For example, China's "Cainiao Post" is a typical logistics alliance mode. Crowdsourcing logistics is actually one of the third party logistics models, in which companies (crowdsourcers) outsource delivery orders via the Internet to uncertain individuals (crowdsourcees) [23]. Typical crowdsourcing logistics companies include "Meituan crowdsourcing" in China and "MyWays" in Sweden. Actually, e-commerce has not only brought about changes in logistics patterns, but also expanded the customers base of logistics service providers. The customers of logistics service providers are not only enterprises. Under the influence of e-commerce, consumers have become the larger customers of logistics service providers [24]. Especially with the increasing popularity of online shopping, more and more parcels in residential areas are delivered to consumers' homes by logistics practitioners [25].

Therefore, in the era of e-commerce, logistics is not only limited to provide services for e-commerce. The development of e-commerce not only promotes the birth of new logistics mode, but also expands the customer base of logistics service providers. In view of this, the impact of 
e-commerce will be fully considered when constructing the indicator system for logistics demand forecast.

\section{Indicators of logistics demand forecasting}

Many scholars have built a diversified logistics demand forecasting indicator system for different situations (see summary in Table 1). For example, Nguyen [26] based on the perspective of logistics development in Southeast Asia, takes GDP, growth rate of total regional logistics, attractiveness of logistics regions, distribution of regional logistics, and regional distance as variables in logistics demand prediction. Fan and Wu [27] selected GDP, total cost of social logistics, total output value of the first, second and third industries, freight volume, goods turnover, total import and export volume, express volume, postal outlets, total retail sales of social consumer goods, and so on as indicators of logistics demand forecast. Han et al. [28] took GDP, total cost of social logistics, investment in social fixed assets, import, and export volume as indicators of logistics demand calculation and prediction. Du and Chen [29] used GDP, post and telecommunications services, total retail sales of social consumer goods, and residents' consumption level as indicators for logistics demand forecasting. The research of the above scholars has a good reference value, which this paper uses to construct the indicator system of logistics demand prediction for e-commerce development in Guangdong province.

However, considering the impact of e-commerce on logistics, it is necessary to reflect on the role of e-commerce in logistics demand forecasting indicators. E-commerce logistics often involves both consumer and enterprise customers. Since sales channels and distribution channels are separated, there are various ways of distribution [24]. In addition, e-commerce demands give rise to a series of logistics activities. For example, locker points of delivery (unattended) and service points of delivery (attended) [25]. Therefore, this paper integrates the relevant indicators of e-commerce into the prediction of Guangdong logistics demand, reflects the scale of logistics demand more realistically, and expands the indicator system of logistics demand.

\section{Methods used in logistics demand forecasting}

Domestic and foreign logistics demand prediction is mainly based on quantitative methods including support vector machine, artificial neural network, linear regression, genetic algorithm, GM $(1,1)$ model, and other single and combined prediction models [30]. For example, Nguyen [26] used the L-OD method to forecast the logistics demand in Southeast Asia. Yan et al. [31] established a logistics demand combination prediction model (grey model and exponential smoothing model) using cargo throughput. Fan and Wu [27] predicted logistics demand using the composite kernel model, and found that this method could improve the prediction accuracy and had good robustness. Han et al. [28] proposed a logistics demand forecasting model based on fuzzy cognitive map. Cao et al. [32] used genetic algorithm and support vector regression machine to predict regional logistics demand. Compared with the above methods, BP neural network has the capacity for non-linear mapping, self-learning and self-adaptation, generalization and fault tolerance [33]. The logistics demand forecasting indicators studied in this paper come from various sources and have non-linear data characteristics among them. Therefore, BP neural network is used to forecast the logistics demand. Meanwhile, to verify the accuracy of the prediction method, the $\operatorname{GM}(1,1)$ is used as the control model.

Through the above analysis, this paper finds that the existing research has provided a wealth of literature on logistics demand forecasting indicators and forecasting models. However, there are relatively few studies on logistics demand forecasting under the influence of e-commerce. Furthermore, in terms of forecasting methods, more combined models are needed to compare the prediction accuracy.

\section{Methodology}

The purpose of this study is to predict the logistics demand scale of Guangdong province in the era of e-commerce. On the basis of literature review, the research process is

Table 1 Logistics demand forecasting indicators under different circumstances

\begin{tabular}{|c|c|c|}
\hline Target & Factors & References \\
\hline \multirow[t]{4}{*}{ Logistics demand forecast } & $\begin{array}{l}\text { GDP, total growth rate of regional logistics, attraction of logistics region, distribution of regional } \\
\text { logistics, regional distance, etc. }\end{array}$ & Nguyen [26] \\
\hline & $\begin{array}{l}\text { GDP, total cost of social logistics, total output value of primary, secondary and tertiary indus- } \\
\text { tries, freight volume, turnover of goods, total import and export volume, express delivery } \\
\text { volume, postal outlets, total retail sales of social consumer goods, etc. }\end{array}$ & Fan and $\mathrm{Wu}[27]$ \\
\hline & $\begin{array}{l}\text { GDP, total cost of social logistics, investment in social fixed assets, import and export volume, } \\
\text { etc. }\end{array}$ & Han et al. [28] \\
\hline & $\begin{array}{l}\text { GDP, post and telecommunications services, total retail sales of consumer goods, household } \\
\text { consumption levels, etc. }\end{array}$ & Du and Chen [29] \\
\hline
\end{tabular}


developed as shown in Fig. 1. The research framework includes the following seven steps:

1. The determination of forecast objects: the prediction of the logistics demand scale of Guangdong province in the e-commerce era.

2. Target setting: forecasting logistics demand for the next 3 years.

3. Literature review: preliminary screening of relevant indicators and collection of indicators data.

4. Application of factor analysis (FA) model: correlation analysis, reliability and validity tests on the indicators of primary election.

5. Construction of an indicator system: after passing the correlation analysis, reliability and validity test, the indicator can be used to construct the index system.

6. The prediction methods $(\operatorname{GM}(1,1)$ model and BP neural network model) were used to predict logistics demand. Then the prediction errors of these two methods were compared.

7. Prediction results: the method with the minimum error is selected to predict the logistics demand of Guangdong for the next 3 years.

To give readers a clear understanding of the research methods used in this paper, the principles and applications of FA model, GM $(1,1)$ model and BP neural network are briefly introduced below.

\section{Factor analysis model}

Factor analysis method was first proposed by psychologist Charles Spearman and was well known by the academic circles in the 1930s [34]. The starting point of factor analysis is to replace most of the information of the original variable with fewer independent factor variables, which can be represented by the following mathematical model [35]: $x_{1}=a_{11} F_{1}+a_{12} F_{2}+\cdots+a_{1 m} F_{m}$,

$x_{2}=a_{21} F_{1}+a_{22} F_{2}+\cdots+a_{2 m} F_{m}$,

$\cdots$

$x_{p}=a_{p 1} F_{1}+a_{p 2} F_{2}+\cdots+a_{p m} F_{m}$,

where $x_{1}, x_{2}, \cdots, x_{p}$ represent $P$ original variables, which are standardized variables with mean value of 0 and standard deviation of $1 . F_{1}, F_{2}, \cdots, F_{m}$ represents $m$ factor variables, and $m$ is less than $P$. Expressed in the matrix form as follows [31]:

$X=A F=\alpha \varepsilon$,

where $F$ is the common factor, which can be understood as $m$ coordinate axes perpendicular to each other in the highdimensional space; $A$ is the factor loading matrix, and is the load of the $i$ th original variable on the $j$ th factor variable.

\section{$\operatorname{GM}(1,1)$ model}

The GM $(1,1)$ model was proposed by Deng [36]. In this method, the approximate exponential law is generated by summing the original data and then the modeling is carried out. This model has been applied by many scholars in various fields. For example, Liu et al. [37], Shen et al. [38], and Wang et al. [39] have, respectively, applied this prediction model to the research of tourism industry, power systems, logistics supply chain and other industries. The basic principle of GM $(1,1)$ model is as follows [36]:

The GM $(1,1)$ model is based on the grey system theory. The differential fitting method is applied to process the various factors in the system as grey data, to establish the prediction model [39]. Its expression formula is [36]

$\hat{y}^{(1)}(k+1)=\left(y^{(0)}(1)-\frac{b}{a}\right) e^{-a k}+\frac{b}{a}$,

where $y^{(0)}(1)$ is the original data of each factor in the regional logistics demand scale system; $\hat{y}^{(1)}(k+1)$ is the one-time accumulation value of the original data for various

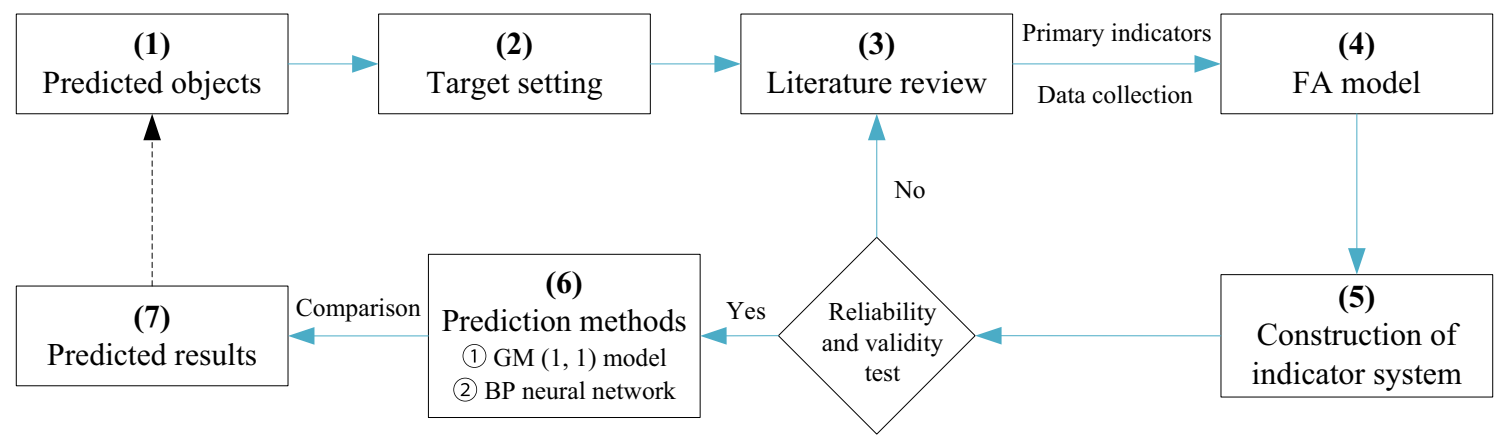

Fig. 1 Research process 
factors in the regional logistics demand scale system; $k$ is time; $a$ is the development grey number; $b$ is the endogenous control grey number.

\section{BP neural network model}

In the mid-1980s, Rumelhart [40] proposed the famous Error Back Propagation (BP), which solved the learning problem of multi-layer neural networks. BP neural network is generally multi-layered. The layers of BP neural network model are input layer, hidden layer and output layer [41]. The hidden layer of BP neural network can be one or more layers. The topological structure of a BP neural network containing two hidden layers is shown in Fig. 2 [41, 42].

BP neural network has the following characteristics [42]:

1. The network is composed of multiple layers with all connections between layers, and no connections between neurons of the same layer

2. The transfer function of BP network must be differentiable. In BP networks, Sigmoid function or linear function is generally used as the transfer function. Sigmoid function can be divided into log-Sigmoid function, and Tan-Sigmoid function depending on whether or not the output value contains negative values. A simple logSigmoid function can be calculated using formula (4):

$$
f(x)=\frac{1}{1+e^{-x}},
$$

where the range of $x$ includes the whole field of real numbers. The function value is between 0 and 1 . In specific applications, parameters can be added to control the position and shape of the curve.

3. Use error BP algorithm for learning.

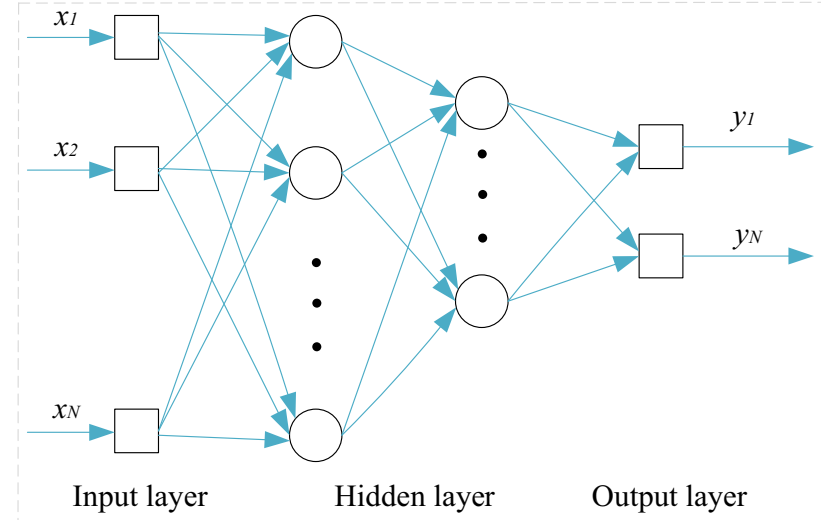

Fig. 2 The structure of BP neural network
BP neural network has been applied to multi-disciplinary prediction. For example, Qin et al. [43], Zhang et al. [44], $\mathrm{Hu}$ [45], respectively, used this method to simulate and predict behavioral recognition, job-shop scheduling problem, and optimization of intelligent logistics distribution center. In view of the extensiveness and reliability of the model in the field of prediction, this study will use this method to predict the logistics demand scale of Guangdong province.

\section{Empirical results}

\section{Construction of indicator system}

As the basic, strategic and leading industry of national economic development, logistics industry plays a vital role in the development of regional economy. Based on literature review, this paper follows the following principles when constructing the logistics demand forecasting indicator system:

1. Reflect the development level of logistics industry as much as possible

2. Meet the requirements of measuring logistics demand

3. Comprehensively consider the availability and reliability of indicator data

4. Reflect the characteristics of the era of e-commerce.

In addition, using the indicators of domestic and foreign scholars such as Ishfaq and Sox [15], Hsiao and Hansen [16], Hsu and Wang [17], Fan and Wu [27], Han et al. [28], Du and Chen [29], etc., this study constructed a target layer using the indicators of Guangdong logistics demand prediction. Taking logistics demand environment, commercial trade environment, basic support environment and e-commerce information environment as latent variables, the indicator system takes 13 indicators such as logistics demand scale as observation variables as summarized in Table 2.

\section{Data source}

The logistics demand scale is used to represent the logistics demand environment. According to the availability and authority of indicators, this paper selects the whole society's cargo transport volume in Statistical Yearbook of Guangdong Province (2000-2019) to calculate the scale of regional logistics demand. Other indicators are also available in the statistical yearbook. The data for this paper were collected in August and September of 2020 when the Guangdong Statistical Yearbook for 2020 had not been published yet. Therefore, relevant data are collected up to 2019.

Since the data of each indicator are different in units, to get more accurate prediction results, this paper has carried 
Table 2 Logistics demand forecasting indicator system

\begin{tabular}{|c|c|c|c|}
\hline Target layer & Latent variables & Observed variables & References \\
\hline \multirow[t]{14}{*}{$\begin{array}{l}\text { Guangdong Logistics Demand Fore- } \\
\text { cast Indicators }\end{array}$} & $W$-logistics demand environment & $\begin{array}{l}Y \text {-logistics demand scale/10 thou- } \\
\text { sand tons }\end{array}$ & Nuzzoloet al. [46] \\
\hline & \multirow[t]{5}{*}{$W_{1}$-commercial trade environment } & $X_{1}$ - GDP/100 million Yuan & \multirow{5}{*}{$\begin{array}{l}\text { Ishfaq and Sox [15] } \\
\text { Fan and Wu [27] } \\
\text { Han et al. [29] } \\
\text { Chen et al. [47] }\end{array}$} \\
\hline & & $X_{2}$ - per capita disposable income/ & \\
\hline & & & \\
\hline & & $\begin{array}{l}X_{3} \text { - total retail sales of consumer } \\
\text { goods/100 million yuan }\end{array}$ & \\
\hline & & $\begin{array}{l}X_{4} \text { - total import and export trade/100 } \\
\text { million yuan }\end{array}$ & \\
\hline & \multirow[t]{4}{*}{$W_{2}$ - basic support environment } & $\begin{array}{l}X_{5} \text { - logistics fixed assets invest- } \\
\text { ment } / 100 \text { million yuan }\end{array}$ & \multirow{4}{*}{$\begin{array}{l}\text { Hsiao and Hansen [16] } \\
\text { Fan and } \mathrm{Wu}[27] \\
\text { Lyu et al. [48] }\end{array}$} \\
\hline & & $\begin{array}{l}X_{6} \text {-number of employees in the } \\
\text { logistics industry/ten thousand } \\
\text { people }\end{array}$ & \\
\hline & & $\begin{array}{l}X_{7} \text {-financial expenditure on logistics } \\
\text { and transportation/100 million yuan }\end{array}$ & \\
\hline & & $X_{8}$-traffic mileage $/ \mathrm{km}$ & \\
\hline & \multirow[t]{4}{*}{$\begin{array}{l}W_{3} \text {-E-commerce information envi- } \\
\text { ronment }\end{array}$} & $\begin{array}{l}X_{9} \text { - total revenue of post and telecom- } \\
\text { munications business } / 100 \text { million } \\
\text { yuan }\end{array}$ & \multirow[t]{4}{*}{$\begin{array}{l}\text { Hsu and Wang [17] } \\
\text { Du and Chen [29] }\end{array}$} \\
\hline & & $\begin{array}{l}X_{10} \text {-internet access users } / 10,000 \\
\text { users }\end{array}$ & \\
\hline & & $\begin{array}{l}X_{11} \text {-number of mobile phone } \\
\text { users/10,000 households }\end{array}$ & \\
\hline & & $\begin{array}{l}X_{12} \text {-investment in information } \\
\text { transmission and internet/100 mil- } \\
\text { lion yuan }\end{array}$ & \\
\hline
\end{tabular}

out dimensionless processing on the original data of each indicator. All indicator data are converted into $[0,1]$. The formula is $x=\left[x_{i j}-\min \left(x_{j}\right)\right] /\left[\max \left(x_{j}\right)-\min \left(x_{j}\right)\right] \quad[49$, 50]. SPSS was used for this process, and then the data are obtained as shown in Table 3.

\section{Correlation degree}

According to the data sorted out in Table 3, the logistics demand scale is associated with 12 indicators. The results are shown in Table 4. The results show that the order of correlation degree between these 12 indicators, and logistics demand scale is $X_{3}>X_{1}>X_{2}>X_{5}>X_{10}>X_{11}>X_{6}>X_{12}>X_{4}$ $>X_{8}>X_{7}>X_{9}$. Since the 12 correlation degree values are all greater than 0.7 and reach the three-level accuracy [35], the 12 indicators selected in this study are applicable to the logistics demand scale prediction.

\section{Multi-factor coupling analysis}

Logistics demand system is a non-linear complex system. In this paper, a variety of influencing factors, such as commercial trade, basic support and e-commerce information, etc. are considered comprehensively. The relationship and restriction among these factors are verified using the multifactor coupling method.

\section{Commercial trading environment}

The commercial trade environment provides an important demand driving force for the development of logistics including regional GDP, per capita disposable income, total retail sales of consumer goods, total import and export trade and other indicators. Through the coupling analysis of logistics demand scale and commercial trade environment by curve fitting, it can be found that logistics demand scale is significantly positively correlated with commercial trade environment. Meanwhile, all $R^{2}$ fitted by the curve passed the significance test, indicating a good effect, as shown in Fig. 3.

\section{Foundation supporting environment}

The basic supporting environment provides an important guarantee for the development of logistics, including the logistics fixed assets investment, the number of employees in the logistics industry, the financial expenditure of logistics and transportation, traffic mileage, and other 
Table 3 Normalized data of Guangdong logistics demand indicators from 2000 to 2019

\begin{tabular}{lllllllllllllll}
\hline Year & $Y$ & $X_{1}$ & $X_{2}$ & $X_{3}$ & $X_{4}$ & $X_{5}$ & $X_{6}$ & $X_{7}$ & $X_{8}$ & $X_{9}$ & $X_{10}$ & $X_{11}$ & $X_{12}$ \\
\hline 2000 & $119,216.00$ & 0.00 & 0.00 & 0.00 & 0.00 & 0.01 & 0.35 & 0.00 & 0.00 & 0.00 & 0.00 & 0.00 & 0.13 \\
2001 & $131,621.00$ & 0.01 & 0.01 & 0.01 & 0.01 & 0.00 & 0.39 & 0.01 & 0.02 & 0.00 & 0.06 & 0.06 & 0.18 \\
2002 & $137,032.00$ & 0.03 & 0.03 & 0.03 & 0.07 & 0.00 & 0.37 & 0.01 & 0.05 & 0.01 & 0.20 & 0.11 & 0.15 \\
2003 & $143,964.00$ & 0.05 & 0.08 & 0.04 & 0.16 & 0.03 & 0.00 & 0.01 & 0.06 & 0.03 & 0.25 & 0.15 & 0.27 \\
2004 & $156,094.00$ & 0.08 & 0.10 & 0.06 & 0.27 & 0.08 & 0.06 & 0.02 & 0.07 & 0.07 & 0.25 & 0.23 & 0.29 \\
2005 & $158,470.00$ & 0.12 & 0.16 & 0.09 & 0.37 & 0.09 & 0.10 & 0.03 & 0.11 & 0.09 & 0.21 & 0.29 & 0.15 \\
2006 & $145,911.00$ & 0.17 & 0.19 & 0.13 & 0.49 & 0.13 & 0.16 & 0.03 & 0.64 & 0.11 & 0.15 & 0.33 & 0.02 \\
2007 & $165,426.00$ & 0.22 & 0.23 & 0.17 & 0.60 & 0.14 & 0.17 & 0.03 & 0.67 & 0.15 & 0.16 & 0.37 & 0.00 \\
2008 & $176,279.00$ & 0.27 & 0.28 & 0.22 & 0.59 & 0.20 & 0.16 & 0.03 & 0.68 & 0.18 & 0.21 & 0.40 & 0.15 \\
2009 & $179,722.00$ & 0.30 & 0.32 & 0.27 & 0.48 & 0.35 & 0.34 & 0.10 & 0.69 & 0.20 & 0.24 & 0.43 & 0.35 \\
2010 & $205,034.00$ & 0.37 & 0.39 & 0.34 & 0.68 & 0.41 & 0.57 & 0.14 & 0.74 & 0.26 & 0.34 & 0.48 & 0.14 \\
2011 & $234,978.00$ & 0.44 & 0.46 & 0.42 & 0.79 & 0.34 & 0.59 & 0.25 & 0.74 & 0.07 & 0.39 & 0.54 & 0.70 \\
2012 & $266,359.08$ & 0.49 & 0.55 & 0.48 & 0.83 & 0.36 & 0.57 & 0.23 & 0.78 & 0.09 & 0.46 & 0.63 & 0.46 \\
2013 & $305,833.00$ & 0.54 & 0.54 & 0.55 & 0.93 & 0.50 & 0.71 & 0.33 & 0.84 & 0.13 & 0.51 & 0.76 & 0.29 \\
2014 & $352,926.00$ & 0.60 & 0.60 & 0.63 & 0.90 & 0.57 & 0.80 & 0.43 & 0.92 & 0.17 & 0.53 & 0.77 & 0.63 \\
2015 & $376,434.00$ & 0.65 & 0.67 & 0.71 & 0.86 & 0.68 & 0.83 & 1.00 & 0.95 & 0.23 & 0.54 & 0.78 & 1.00 \\
2016 & $377,645.00$ & 0.72 & 0.74 & 0.79 & 0.85 & 0.66 & 0.86 & 0.50 & 0.97 & 0.20 & 0.69 & 0.74 & 0.83 \\
2017 & $400,601.00$ & 0.81 & 0.82 & 0.88 & 0.94 & 0.85 & 0.92 & 0.41 & 0.98 & 0.34 & 0.81 & 0.76 & 0.82 \\
2018 & $424,996.00$ & 0.89 & 0.91 & 0.92 & 1.00 & 0.85 & 0.95 & 0.29 & 0.97 & 0.65 & 0.91 & 0.88 & 0.71 \\
2019 & $446,050.00$ & 1.00 & 1.00 & 1.00 & 1.00 & 1.00 & 1.00 & 0.42 & 1.00 & 1.00 & 1.00 & 1.00 & 0.84 \\
\hline
\end{tabular}

Table 4 Correlation degree between logistics demand scale and other indicators

\begin{tabular}{lll}
\hline Indicators & Correlation degree & Sig. (double tails) \\
\hline$X_{1}$ & $0.980^{* *}$ & 0.0000 \\
$X_{2}$ & $0.976^{* *}$ & 0.0000 \\
$X_{3}$ & $0.990^{* *}$ & 0.0000 \\
$X_{4}$ & $0.872^{* *}$ & 0.0000 \\
$X_{5}$ & $0.975^{* *}$ & 0.0000 \\
$X_{6}$ & $0.920^{* *}$ & 0.0000 \\
$X_{7}$ & $0.815^{* *}$ & 0.0000 \\
$X_{8}$ & $0.825^{* *}$ & 0.0000 \\
$X_{9}$ & $0.739^{* *}$ & 0.0002 \\
$X_{10}$ & $0.965^{* *}$ & 0.0000 \\
$X_{11}$ & $0.949^{* *}$ & 0.0000 \\
$X_{12}$ & $0.881^{* *}$ & 0.0000 \\
\hline
\end{tabular}

$* * p<0.01$

$* p<0.05$

indicators. Through the coupling analysis of logistics demand scale and foundation supporting environment by curve fitting, it can be found that logistics demand scale and foundation supporting environment also present a high positive correlation. All $R^{2}$ fitted by the curve passed the significance test with good results, as shown in Fig. 4.

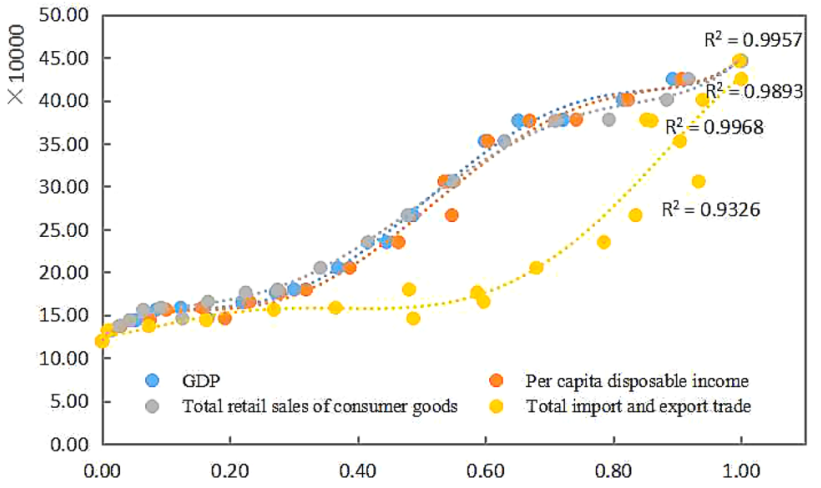

Fig. 3 Coupling analysis of logistics demand scale and commercial trade environment

\section{E-commerce information environment}

E-commerce information environment provides an important driving force for the development of logistics including the total revenue of post and telecommunications business, internet access users, number of mobile phone users, investment in information transmission, and internet. Through the coupling analysis of logistics demand scale and e-commerce information environment by curve fitting, it can be found that logistics demand scale is significantly positively correlated with e-commerce information environment. In addition, $R^{2}$ fitted by the curve passed the significance test, indicating a good effect, as shown in Fig. 5. 


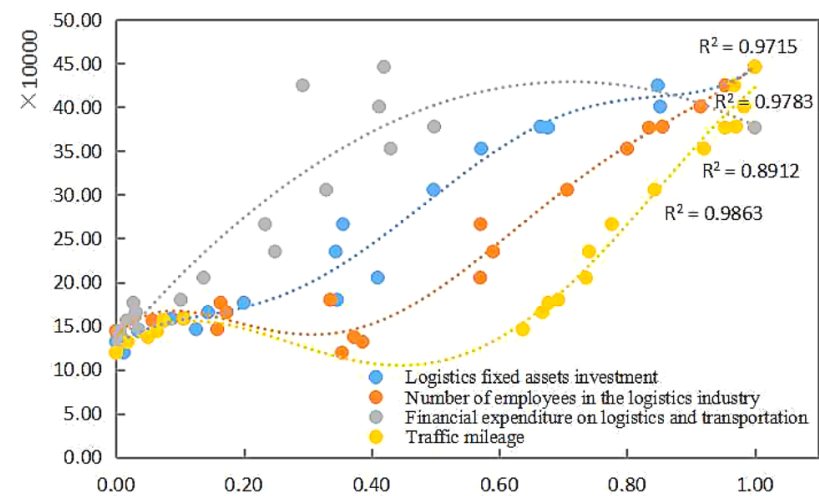

Fig. 4 Coupling analysis of logistics demand scale and basic supporting environment

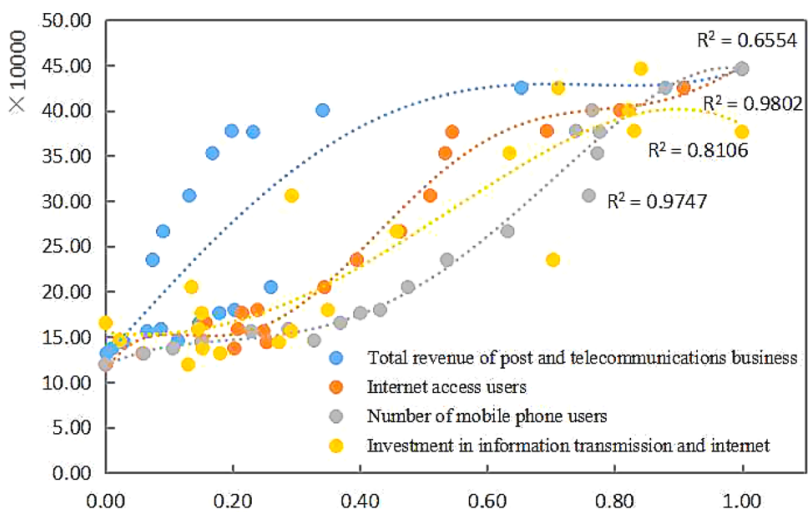

Fig. 5 Coupling analysis of logistics demand scale and e-commerce information environment

\section{Principal component coupling analysis}

The curve fitting method is adopted to conduct a coupling analysis of the logistics demand scale with the commercial and trade environment, the basic supporting environment, and the e-commerce information environment. It can be found that the logistics demand scale has a significant non-linear positive correlation with the indicators of these three aspects. However, the $R^{2}$ value of posts and telecommunications revenue, information transmission, internet investment and other indicators is not high. Therefore, factor analysis is used to reduce the dimension of these indicators.

The specific operation method is as follows: the data are imported into SPSS for factor analysis. The KMO value was greater than 0.6, and the significance of Bartlett sphericity test was 0.000 . This means that these indicators were suitable for factor analysis. The cumulative contribution rate of the three factors extracted by dimension reduction reached $96.23 \%$, indicating that all information could be comprehensively reflected [35].

According to formula (5) and formula (6), the scores of $F_{1}, F_{2}$ and $F_{3}$ can be calculated. The formula is as follows [35]:

$F_{i}=C_{i} * X$,

$F_{i}=\left[\begin{array}{l}F_{1} \\ F_{2} \\ F_{3}\end{array}\right], \quad C_{i}=\left[\begin{array}{l}C_{1} \\ C_{2} \\ C_{3}\end{array}\right]=\left[\begin{array}{lllll}0.299 & 0.304 & 0.282 & \cdots & 0.134 \\ 0.266 & 0.264 & 0.295 & \cdots & 0.435 \\ 0.316 & 0.311 & 0.304 & \cdots & 0.196\end{array}\right]$,

$X=\left[\begin{array}{c}X_{01} \\ X_{02} \\ \cdots \\ X_{34}\end{array}\right]$,

$F=\frac{\lambda_{1}}{\lambda_{1}+\lambda_{2}+\lambda_{3}} * F_{1}+\frac{\lambda_{2}}{\lambda_{1}+\lambda_{2}+\lambda_{3}} * F_{2}+\frac{\lambda_{3}}{\lambda_{1}+\lambda_{2}+\lambda_{3}} * F_{3}$,

where $\lambda_{1}, \lambda_{2}$ and $\lambda_{3}$ are the corresponding eigenvalues of each principal component, which are, respectively, 4.040, 3.876 and 3.632. The principal component scores and the comprehensive scores are shown in Table 5.

Through the coupling analysis of logistics demand scale with $F_{1}, F_{2}$ and $F_{3}$ by curve fitting again, it can be found that logistics demand scale presents significant non-linear

Table 5 Principal component scores and factor synthesis scores

\begin{tabular}{lllll}
\hline Year & $F_{1}$ & $F_{2}$ & $F_{3}$ & $F$ \\
\hline 2000 & 0 & 0 & 0 & 0 \\
2001 & 0.22 & 0.25 & 0.22 & 0.23 \\
2002 & 0.53 & 0.47 & 0.54 & 0.52 \\
2003 & 0.68 & 0.49 & 0.64 & 0.61 \\
2004 & 1.1 & 0.83 & 1.02 & 0.99 \\
2005 & 1.41 & 0.9 & 1.21 & 1.18 \\
2006 & 2.3 & 1.23 & 1.63 & 1.73 \\
2007 & 2.68 & 1.46 & 1.97 & 2.05 \\
2008 & 3.03 & 1.92 & 2.43 & 2.47 \\
2009 & 3.47 & 2.74 & 3.02 & 3.09 \\
2010 & 4.27 & 3.26 & 3.76 & 3.77 \\
2011 & 4.91 & 4.49 & 4.11 & 4.52 \\
2012 & 5.24 & 4.47 & 4.38 & 4.71 \\
2013 & 5.97 & 5.02 & 5 & 5.35 \\
2014 & 6.62 & 6.07 & 5.72 & 6.15 \\
2015 & 7.57 & 7.87 & 6.53 & 7.35 \\
2016 & 7.36 & 7.08 & 6.63 & 7.04 \\
2017 & 8.05 & 7.6 & 7.62 & 7.77 \\
2018 & 8.57 & 7.76 & 8.63 & 8.32 \\
2019 & 9.61 & 8.89 & 10.14 & 9.54 \\
\hline & & & & \\
\hline
\end{tabular}

To predict the data more effectively, the principal component score and the factor synthesis score obtained were de-negated 
positive correlation with these three principal components. Simultaneously, the $R^{2}$ fitted by the curve passed the significance test and were all greater than 0.95 , indicating a good effect [35], as shown in Fig. 6.

The formula of curve fitting is as follows:

$$
\begin{aligned}
y= & 52.728 F_{1}^{5}-1427.7 F_{1}^{4}+13168 F_{1}^{3}-44869 F_{1}^{2} \\
& +66787 F_{1}+117663\left(R^{2}=0.9972\right), \\
y= & 99.921 F_{2}^{5}-2311.2 F_{2}^{4}+18331 F_{2}^{3}-55377 F_{2}^{2} \\
& +80253 F_{2}+115592\left(R^{2}=0.9887\right), \\
y= & 72.221 F_{3}^{5}-1787.6 F_{3}^{4}+14601 F_{3}^{3}-42265 F_{3}^{2} \\
& +59853 F_{3}+119690\left(R^{2}=0.9949\right) .
\end{aligned}
$$

\section{Data prediction and results}

\section{Predictions of the $\mathrm{GM}(1,1)$ model}

The GM $(1,1)$ model simulation fitting sequence $G$ and simulation error sequence $E$ is calculated using GTMS7.0 software:

$G=(119,216.00,131,621.00,137,032.00,143,964.00$, $156,094.00,158,470.00,145,911.00,165,426.00$, $176,279.00,179,722.00,205,034.00,234,978.00$, $266,359.08,305,833.00,352,926.00,376,434.00$, 377,645.00, 400,601.00, 424,996.00, 446,050.00);

$E=(0.000,-19,792.391,-15,982.116,-12,932.464$,

- 14,257.735, - 4938.058, 20,281.032, 14,470.060, $18,451.109,31,065.359,23,134.674,12,005.234,990.140$, - 16,438.427, -39,668.240, - 37,345.319, - 10,595.406, - 3284.864, 5082.427, 19,492.263).

The grey error sequence $E$ is treated non-negatively, and then Eviews8.0 was used for ADF test. It can be found that at the significance level of 0.05 , the null hypothesis of the

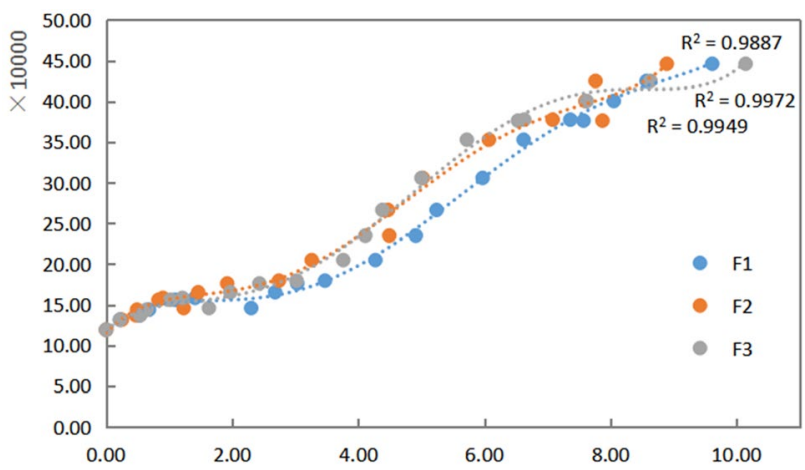

Fig. 6 Coupling analysis of logistics demand scale and principal component
Table 6 ADF test for prediction error

\begin{tabular}{lll}
\hline & $t$ statistic & Prob.* \\
\hline $\begin{array}{l}\text { Augmented Dickey-fuller test } \\
\text { statistic }\end{array}$ & -4.055382 & 0.0077 \\
$\begin{array}{l}\text { Test critical values } \\
1 \% \text { level }\end{array}$ & \\
$5 \%$ level & -3.92035 & \\
$10 \%$ level & -3.065585 & \\
\hline
\end{tabular}

existence of unit root is rejected, which indicates that the error sequence $E$ is a stationary sequence [51]. The test results are shown in Table 6.

The GM $(1,1)$ method was used for modeling and predicted the logistics demand scale of Guangdong province from 2000 to 2019, as shown in Table 7.

The grey model development coefficient $a$ is -0.079 and the grey action coefficient $b$ is 98010.607 . Obviously, $-a<0.3$ indicates that the prediction accuracy is high, and that the $\operatorname{GM}(1,1)$ model established can be used for medium- and long-term prediction [51].

Therefore, by drawing the actual value of logistics demand scale and the predicted value by GM $(1,1)$ model, it is found that there is a large error between the predicted value and the actual value as shown in Fig. 7.

Table 7 Prediction results of GM $(1,1)$ model

\begin{tabular}{llllc}
\hline Year & Actual value & Predicted value & Residual error & Error rate $(\%)$ \\
\hline 2000 & 119,216 & 119,216 & 0 & 0.00 \\
2001 & 131,621 & $111,828.609$ & $-19,792.391$ & -15.04 \\
2002 & 137,032 & $121,049.884$ & $-15,982.116$ & -11.66 \\
2003 & 143,964 & $131,031.536$ & $-12,932.464$ & -8.98 \\
2004 & 156,094 & $141,836.265$ & $-14,257.735$ & -9.13 \\
2005 & 158,470 & $153,531.942$ & -4938.058 & -3.12 \\
2006 & 145,911 & $166,192.032$ & $20,281.032$ & 13.90 \\
2007 & 165,426 & $179,896.06$ & $14,470.06$ & 8.75 \\
2008 & 176,279 & $194,730.109$ & $18,451.109$ & 10.47 \\
2009 & 179,722 & $210,787.359$ & $31,065.359$ & 17.29 \\
2010 & 205,034 & $228,168.674$ & $23,134.674$ & 11.28 \\
2011 & 234,978 & $246,983.234$ & $12,005.234$ & 5.11 \\
2012 & $266,359.08$ & $267,349.224$ & 990.14 & 0.37 \\
2013 & 305,833 & $289,394.573$ & $-16,438.427$ & -5.38 \\
2014 & 352,926 & $313,257.76$ & $-39,668.24$ & -11.24 \\
2015 & 376,434 & $339,088.681$ & $-37,345.319$ & -9.92 \\
2016 & 377,645 & $367,049.594$ & $-10,595.406$ & -2.81 \\
2017 & 400,601 & $397,316.136$ & -3284.864 & -0.82 \\
2018 & 424,996 & $430,078.427$ & 5082.427 & 1.20 \\
2019 & 446,050 & $465,542.263$ & $19,492.263$ & 4.37 \\
\hline & & & &
\end{tabular}

where the prediction model is

$Y(k+1)=1,359,856.5949 * e^{0.079 k}-1240640.5949(k=1,2,3 \ldots 19)$ 


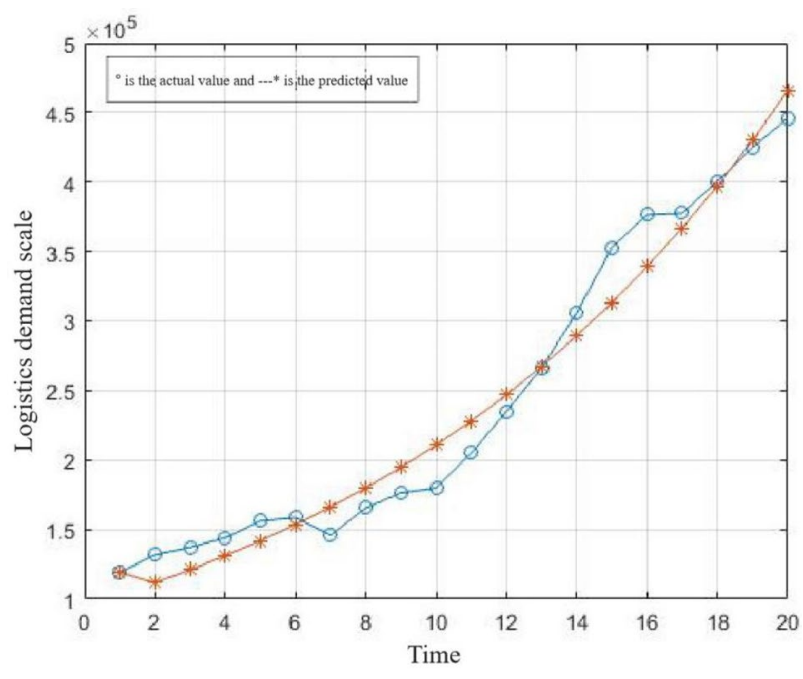

Fig. 7 Comparison between $\operatorname{GM}(1,1)$ model prediction results and actual values

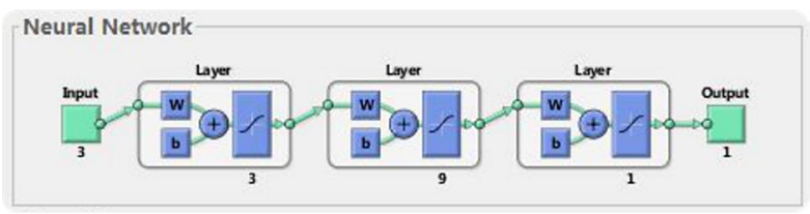

Fig. 8 BP neural network prediction model

\section{Prediction of the BP neural network model}

Based on the three-layer BP neural network for modeling and prediction, this paper determined that the BP network input was 3 (namely the 3 principal component scores calculated above). The logistics demand scale of Guangdong province was taken as the output of the network. According to Kolmogorov theorem, the number of neurons in the hidden layer has the following functional relationship with the number of neurons in the input layer and output layer [42]:

$K=\sqrt{m+n}+a$,

where $n$ and $m$ are the number of input and output neurons, and $a$ is a constant whose value is between 1 and 10 .

According to the empirical formula and repeated training test, when the number of hidden layer neurons is determined as 9 , the prediction effect is the best. The BP neural network prediction model is obtained as shown in Fig. 8.

Matlab was used for BP neural network training. The error trend, training state and regression fitting results are shown in Figs. 9, 10 and 11, respectively.

Then the input layer matrix $B$ and the output layer matrix $P$ are constructed:

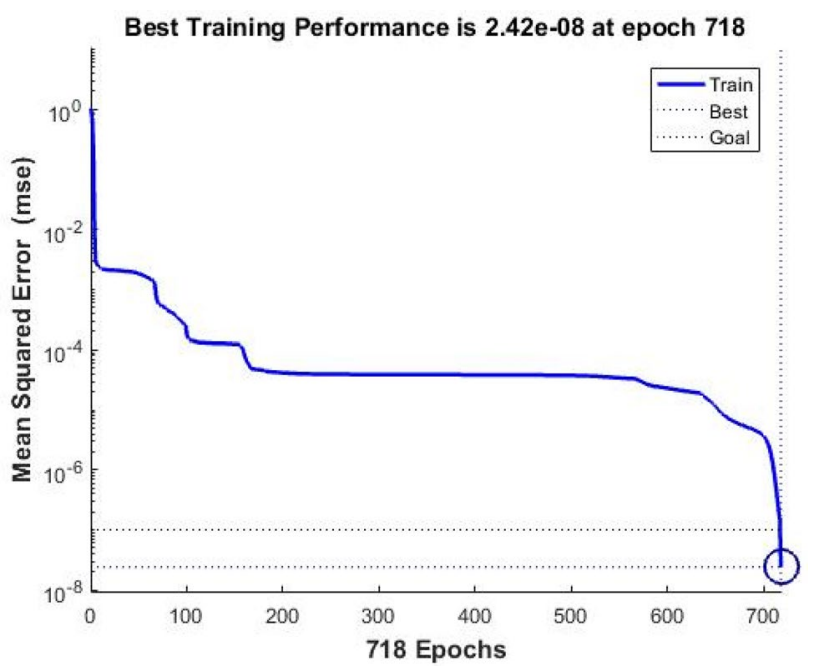

Fig. 9 Results and trends of mean square error

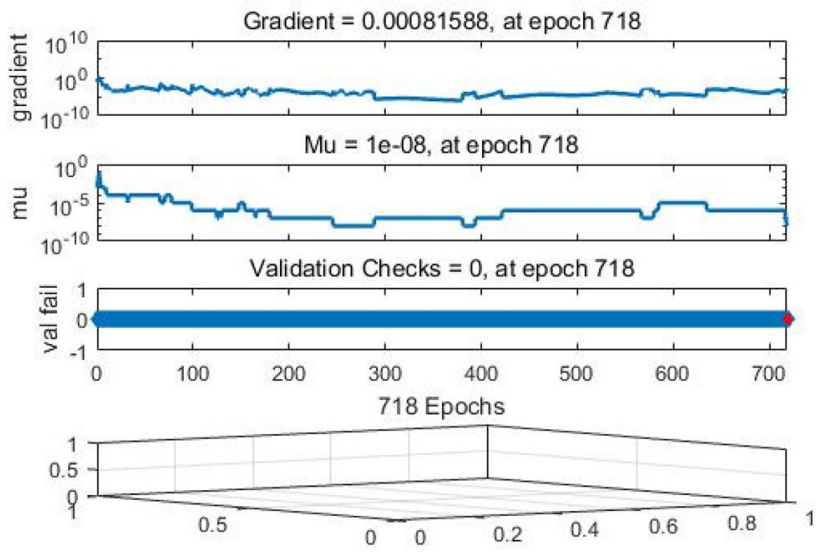

Fig. 10 Training status of BP neural network

$B=\left[\begin{array}{ccc}0.000 & 0.000 & 0.000 \\ 0.2254 & 0.2303 & 0.2639 \\ \vdots & \vdots & \vdots \\ 8.5245 & 7.9414 & 8.2573 \\ 9.6410 & 9.0015 & 9.7187\end{array}\right], \quad P=\left[\begin{array}{c}119216.00 \\ 131621.00 \\ \vdots \\ 424996.00 \\ 446050.00\end{array}\right]$

The trained network was used to predict each group of data. The comparison between the actual value and the predicted value is shown in Fig. 12. It is found that the error between the BP neural network model predicted value and the actual value is small, indicating that the BP neural network prediction model has a high prediction accuracy.

The actual value, BP neural network model predicted value, and BP neural network prediction error value are shown in Table 8. 


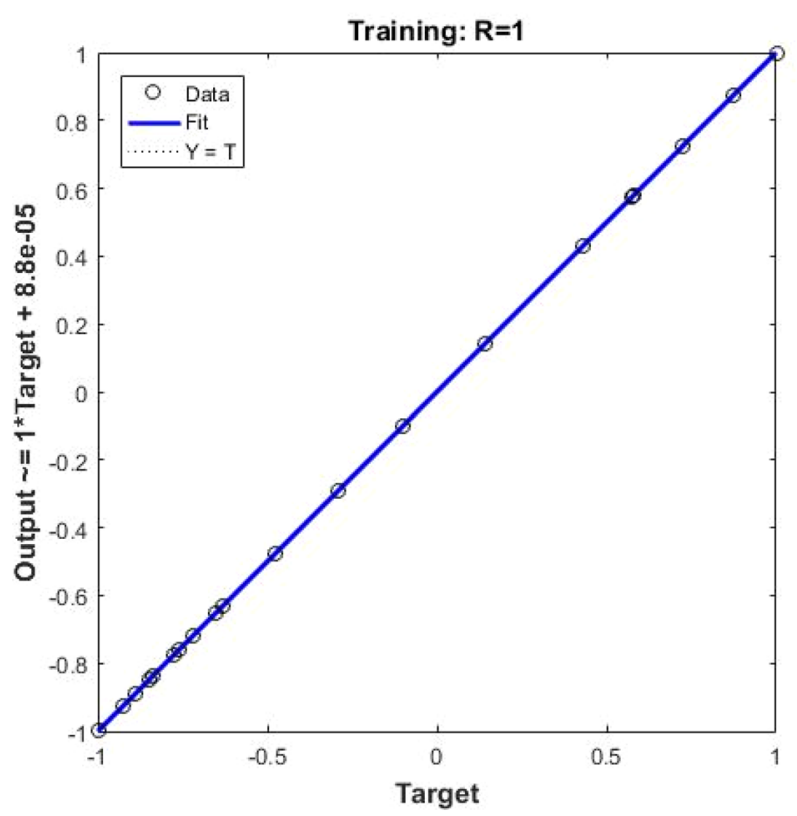

Fig. 11 Regression fitting results

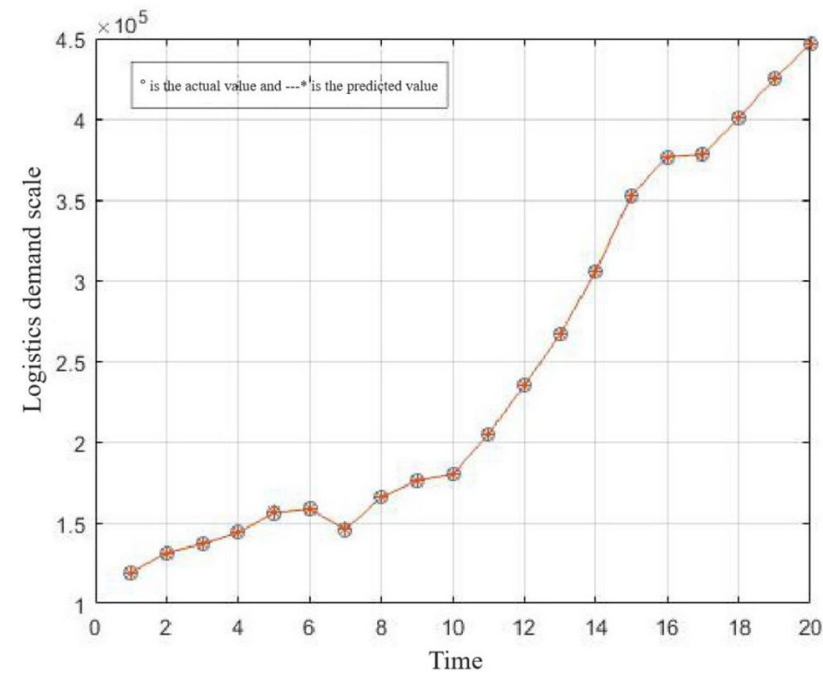

Fig. 12 Comparison of actual and BP neural network model predicted values

\section{Comparison of prediction errors}

To further verify the accuracy and validity of GM $(1,1)$ model and BP neural network model, three error measurement methods (Mean Absolute Error (MAE), Root Mean Square Error (RMSE) and Mean Absolute Percentage Error (MAPE)) were used to evaluate the two prediction methods' accuracies. The three error measurement methods expressions are, respectively [52-54]:
Table 8 Prediction results of BP neural network model

\begin{tabular}{llccc}
\hline Year & Actual value & Predicted value & Residual error & Error rate $(\%)$ \\
\hline 2000 & 119,216 & $119,233.969$ & 17.969 & 0.02 \\
2001 & 131,621 & $131,574.970$ & -46.03 & -0.04 \\
2002 & 137,032 & $137,051.779$ & 19.779 & 0.01 \\
2003 & 143,964 & $143,985.284$ & 21.284 & 0.02 \\
2004 & 156,094 & $156,147.886$ & 53.886 & 0.04 \\
2005 & 158,470 & $158,515.653$ & 45.653 & 0.03 \\
2006 & 145,911 & $145,926.985$ & 15.985 & 0.01 \\
2007 & 165,426 & $165,442.363$ & 16.363 & 0.01 \\
2008 & 176,279 & $176,295.269$ & 16.269 & 0.01 \\
2009 & 179,722 & $179,741.884$ & 19.884 & 0.01 \\
2010 & 205,034 & $205,059.561$ & 25.561 & 0.01 \\
2011 & 234,978 & $235,011.025$ & 33.025 & 0.01 \\
2012 & $266,359.08$ & $266,389.459$ & 30.375 & 0.01 \\
2013 & 305,833 & $305,857.319$ & 24.319 & 0.01 \\
2014 & 352,926 & $352,936.485$ & 10.485 & 0.00 \\
2015 & 376,434 & $376,439.271$ & 5.271 & 0.00 \\
2016 & 377,645 & $377,652.385$ & 7.385 & 0.00 \\
2017 & 400,601 & $400,605.058$ & 4.058 & 0.00 \\
2018 & 424,996 & $424,997.137$ & 1.137 & 0.00 \\
2019 & 446,050 & $446,049.909$ & -0.091 & 0.00 \\
\hline & & & &
\end{tabular}

Table 9 Comparison of prediction errors between GM (1.1) model and BP neural network model

\begin{tabular}{llll}
\hline Prediction method & MAE & RMSE & MAPE (\%) \\
\hline GM $(1,1)$ & $16,010.36591$ & $71,600.53305$ & 7.938 \\
BP neural network & 20.74051832 & 92.75441773 & 0.008 \\
\hline
\end{tabular}

$\mathrm{MAE}=\frac{1}{t} \sum_{j=1}^{t}\left|{ }_{j}^{\wedge}-Y_{j}\right|$

$\mathrm{RMSE}=\sqrt{\frac{1}{t} \sum_{j=1}^{t}\left(\hat{Y}_{j}-Y_{j}\right)^{2}}$,

MAPE $=\frac{1}{t} \sum_{j=1}^{t}\left|\frac{\hat{Y}_{j}-Y_{j}}{Y_{j}}\right| \times 100 \%$,

where $\hat{Y}_{j}$ is the predicted value of logistics demand scale, $Y_{j}$ is the actual value of logistics demand scale, $t$ is the total number of training samples and inspection samples. According to statistics, the prediction accuracy evaluation results of GM $(1,1)$ model and BP neural network model are shown in Table 9. 
It can be seen from Table 9 that the MAE, RMSE and MAPE of BP neural network prediction model are the smallest among the two prediction methods. Among them, the prediction error of BP neural network is generally less than $0.05 \%$ and the average absolute percentage error is $0.008 \%$. This indicates that the BP neural network model is more accurate than GM $(1,1)$ model, and it has better application and popularization value.

\section{Prediction of logistics demand scale}

The established BP neural network prediction model was applied, and combined the $F_{1}, F_{2}$ and $F_{3}$ prediction scores under the time series (see Fig. 13 for details) to predict the logistics demand scale of Guangdong province in 2020-2022. The predicted results are 476,128,600 tons, $483,276,440$ tons and 4,845,766,100 tons, respectively, as shown in Table 10. The predicted data show that from 2000 to 2022 , the scale of logistics demand in Guangdong province will increase from 119,216 to $4,845,766,100$ tons with an average annual growth rate of $6.74 \%$.

The logistics industry is a vital basic industry supporting economic development. To understand the significance of each variable is conducive to identifying the key factors driving the development of logistics demand. The rotated principal component matrix was sorted out, and data less than 0.58 were eliminated to obtain the importance of principal component variables, as shown in Table 11.

It can be seen from Table 11 that the importance of the three principal component variables to the regional logistics demand scale is ranked as $F_{1}>F_{2}>F_{3}$. In $F_{1}$, traffic mileage
Table 10 Logistics demand scale of Guangdong Province from 2020 to 2022

\begin{tabular}{cllrl}
\hline Year & Logistics demand scale & $F_{1}$ & \multicolumn{1}{c}{$F_{2}$} & \multicolumn{1}{l}{$F_{3}$} \\
\hline 2020 & $476,128.60$ & 10.1200 & 9.3600 & 11.7200 \\
2021 & $483,276.44$ & 10.6200 & 9.8300 & 13.3700 \\
2022 & $484,576.61$ & 11.1300 & 10.2900 & 15.1000 \\
\hline
\end{tabular}

and total import and export trade became the most important influencing factors. In $F_{2}$, financial expenditure on logistics and transportation, investment in information transmission and internet are the crucial variables. In $F_{3}$, GDP and logistics fixed assets investment are the most significant influencing factors.

\section{Discussion}

On the basis of previous studies, considering the impact of e-commerce on logistics demand, this paper forecasts the logistics demand of Guangdong from 2020 to 2022. Before the logistics demand forecast, the establishment of a related indicator system is very important. So far, many researchers (e.g., Nguyen [26]; Fan and Wu [27]; Du and Chen [29]) have paid attention to indicators such as regional GDP, per capita disposable income, total retail sales of social consumer goods, total import and export trade, fixed asset investment in the logistics industry, number of employees in the logistics industry, financial expenditure in logistics and transportation, and mileage of vehicles. However, indicators related to e-commerce are less considered. As the
Fig. 13 Predicted scores of $F_{1}$, $F_{2}$ and $F_{3}$ under the time series
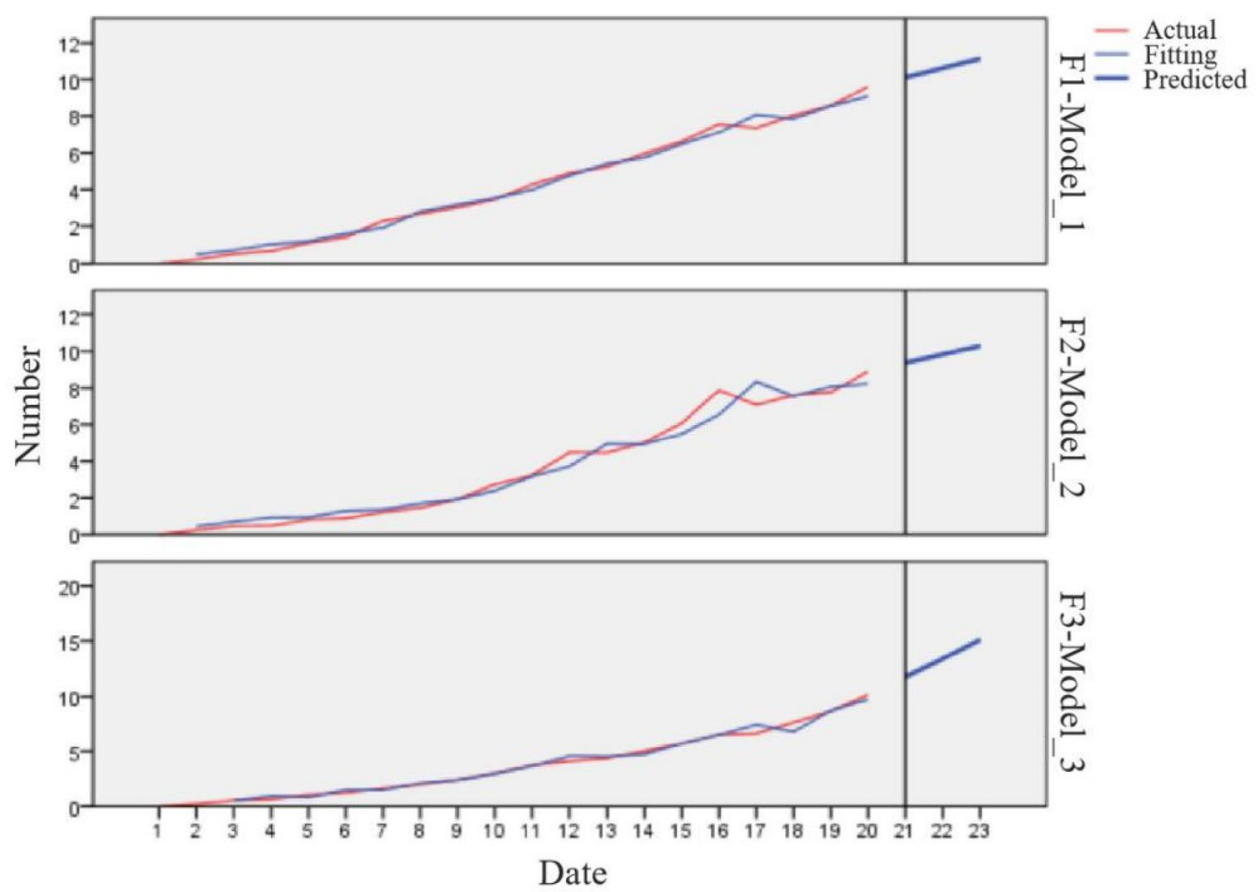
Table 11 Importance degree of principal component variables

\begin{tabular}{llll}
\hline Principal component variables & $F_{1}$ & $F_{2}$ & $F_{3}$ \\
\hline Traffic mileage & 0.865 & \\
Total import and export trade & 0.845 & \\
Number of mobile phone users & 0.719 & \\
Per capita disposable income & 0.611 & \\
Financial expenditure on logistics and transportation & & 0.859 \\
Investment in information transmission and internet & & 0.856 \\
Number of employees in the logistics industry & & 0.674 & \\
Total retail sales of consumer goods & & 0.580 & \\
GDP & & & 0.917 \\
Logistics fixed assets investment & & 0.700 \\
Total revenue of post and telecommunications business & & \\
Internet access users & & & 0.625 \\
\hline
\end{tabular}

first creative point, in this paper, e-commerce information environment factors such as total revenue of post and telecommunications services, internet access users, number of mobile phone users, information transmission and internet investment are incorporated into the Guangdong logistics demand indicator system. This reflects the historical background and realistic situation of logistics demand. For the second creative point, the comparison between GM (1, 1) model and BP neural network model provides a more accurate choice for Guangdong logistics demand prediction (comparison with Fan and Wu [27], Han et al. [28], Wang and Yan [30], Cao et al. [32]). These findings enrich the research foundation of related fields. Based on the above findings, this paper proposes the theoretical and practical implications below.

\section{Theoretical implications}

From the perspective of e-commerce, the logistics demand prediction indicator system of Guangdong was constructed, and GM $(1,1)$ model and BP neural network model were used to make the prediction. This study has three theoretical contributions.

First, this paper constructs the Guangdong logistics demand forecasting indicator system by considering the development background of e-commerce. Logistics and e-commerce no longer have the relationship between service and being served $[19,20]$. Also, in the previous literature on regional logistics demand forecasting, the relevant indicators of e-commerce are rarely considered (e.g., Nguyen [26]; Fan and Wu [27]; Han et al. [28]). Based on the historical background of e-commerce, this paper considers the related indicators of e-commerce driving logistics demand, and provides a new perspective for the establishment of regional logistics demand indicator systems.

Second, this paper enriches the literature of regional logistics demand forecasting. With the rapid development of mobile e-commerce, online shopping has become the living habit of the vast majority of residents. The resulting logistics order accumulation, regional logistics, and distribution capacity is insufficient and other problems frequently occur $[13,14]$. By forecasting the logistics demand in Guangdong, this paper provides ideas and reference for solving the above problems, and embodies the value of regional logistics demand forecasting.

Third, this paper expands the application of GM $(1,1)$ model and BP neural network model in regional logistics demand forecasting. The results show that GM $(1,1)$ model and BP neural network model have a good application prospect in regional logistics demand prediction, and BP neural network model has a relatively small prediction error and a relatively better prediction effect. Meanwhile, the findings of this study are consistent with those of Du and Chen [29], and Wang et al. [55], which is helpful to promote the prediction and application of BP neural network model in regional logistics demand, last kilometer logistics demand, crowdsourcing logistics demand and other aspects.

\section{Practical implications}

From a practical point of view, the insights provided by our study can provide recommendations for logistics enterprises and relevant e-commerce platforms. This study has three practical implications.

First, relevant e-commerce platforms should pay attention to the prediction of regional logistics demand, especially in the peak period of logistics delivery such as a shopping carnival. During peak delivery periods and shopping carnivals, there are often too many orders to make the logistics work $[13,14]$. Forecasting the possible logistics demand in advance can alleviate the problem, and provide suggestions for the implementation of relevant measures.

Second, e-commerce platforms and logistics enterprises should choose scientific forecasting methods when they

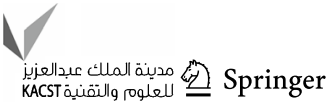


make regional logistics demand predictions. The BP neural network model has better predictive effect than GM $(1,1)$ model. This finding is consistent with the results of Du and Chen [29] and Wang et al. [55]. Scientific and accurate prediction results can provide a reasonable reference for e-commerce platforms, and logistics enterprises to make decisions with the greatest effectiveness. Therefore, it is necessary for relevant enterprises to further study the function and role of BP neural network model in logistics demand prediction.

Finally, logistics companies should encourage experimentation with new distribution patterns (e.g., crowdsourcing logistics, and logistics alliances). In addition to the prediction of regional logistics demand, the implementation of new distribution modes by logistics enterprises is also helpful to alleviate problems such as insufficient capacity, and delay of logistics delivery during peak periods [13, 22]. Meanwhile, the new distribution modes can better integrate with e-commerce to realize the mutual assistance cycle between logistics and e-commerce.

\section{Conclusions}

The development of e-commerce is both an opportunity and a challenge for logistics. On the one hand, the e-commerce drives the logistics to change unceasingly, and has promoted the regional logistics demand scale. On the other hand, the rapid growth of e-commerce orders has also put great pressure on logistics distribution. To alleviate and solve the issue of mismatch between regional logistics demand and e-commerce growth rate, a logistics demand forecasting indicator system from the perspective of e-commerce was built. Then this indicator system was applied, combined with GM (1, 1) model and BP neural network model, to predict regional logistics demand. The results show that this indicator system can better reflect the quantification standard of the current regional logistics demand scale. Also, this study found that BP neural network model has a good effect in prediction of regional logistics demand. The findings of this study are helpful for people to re-understand the relationship between e-commerce and logistics, and to pay attention to the key factors driving regional logistics demand.

However, there are some limitations in this study. First, the indicator system of regional logistics demand prediction is based on the perspective of e-commerce, which may be different from other viewpoints. Logistics demand is not only affected by e-commerce. There are other factors such as the distribution mode of logistics enterprises, the structure of consumer groups and other factors that cannot be ignored. Therefore, it is necessary to expand the regional logistics prediction indicator system to other diverse perspectives in future studies. Second, this study only compared the prediction results of $\operatorname{GM}(1,1)$ model and BP neural network model. Obviously, Kalman filter prediction model, combination prediction model and regression prediction method are also good prediction model choices. In the future, comparative studies between these different forecasting methods and the BP neural network model should be added. Finally, the problem of how to combine the new distribution mode with the logistics demand forecasting model to achieve the goal of ameliorating the distribution efficiency of logistics enterprises still needs to be deeply discussed and solved. In other words, regional logistics demand prediction plays an early warning and guiding role for e-commerce platforms and logistics enterprises. Therefore, the research work related to it is worth continuous optimization.

Acknowledgements The authors thank the editor and anonymous reviewers for their numerous constructive comments, and encouragement that have improved the paper greatly.

Funding This study was funded by National Social Science Foundation Project under Grant nos. 18BGL236, 19BGL177, and the MOE (Ministry of Education in China) Project of Humanity and Social Science Foundation under Grant no. 18YJA630001.

\section{Compliance with ethical standards}

Conflict of interest There are no conflicts of interests.

Open Access This article is licensed under a Creative Commons Attribution 4.0 International License, which permits use, sharing, adaptation, distribution and reproduction in any medium or format, as long as you give appropriate credit to the original author(s) and the source, provide a link to the Creative Commons licence, and indicate if changes were made. The images or other third party material in this article are included in the article's Creative Commons licence, unless indicated otherwise in a credit line to the material. If material is not included in the article's Creative Commons licence and your intended use is not permitted by statutory regulation or exceeds the permitted use, you will need to obtain permission directly from the copyright holder. To view a copy of this licence, visit http://creativecommons.org/licenses/by/4.0/.

\section{References}

1. Geng J, Li C (2019) Empirical research on the spatial distribution and determinants of regional e-commerce in China: evidence from Chinese provinces. Emerg Mark Financ Trade 14(C31):1-17

2. Su ML (2019) 1997-2019: the 22nd anniversary of e-commerce development and its future. Comput Netw 45(19):8-10

3. Gibbs J, Kraemer KL, Dedrick J (2003) Environment and policy factors shaping global e-commerce diffusion: a cross-country comparison. Inform Soc 19(1):5-18

4. Hawk S (2004) A comparison of B2C e-commerce in developing countries. Electron Commer Res 4(3):181-199

5. Wang F (2017) Study on e-commerce development strategies of cross-border international trade in China. In: International conference on humanities science, management and education technology, pp 298-302

6. Inoue Y, Hashimoto M, Takenaka T (2019) Effectiveness of ecosystem strategies for the sustainability of marketplace platform ecosystems. Sustainability 11(20):1-33 
7. Hsiao YH, Chen MC, Liao WC (2017) Logistics service design for cross-border e-commerce using Kansei engineering with text-mining-based online content analysis. Telemat Inform 34(4):283-302

8. Kim TY, Dekker R, Heij C (2017) Cross-border electronic commerce: distance effects and express delivery in European Union markets. Int J Electron Comm 21(2):184-218

9. China Reporting Net (2020) China Federation of Logistics and Purchasing: China e-commerce logistics market analysis report in 2020 - an analysis of current industrial scale and development trend. http://baogao.chinabaogao.com/wuliu/430349430349.html. Accessed 16 Sep 2020

10. Devari A, Nikolaev AG, He Q (2017) Crowdsourcing the last mile delivery of online orders by exploiting the social networks of retail store customers. Transport Res E-Log 105:105-122

11. Bin H, Wang HF, Xie GJ (2019) Study on the influencing factors of crowdsourcing logistics under sharing economy. Manage Rev 31(8):219-229

12. Wang J, Lu W (2018) The researches on the development strategy of e-commerce and logistics based on dynamic game theory. Int Conf Intell Transp Big Data Smart City 2018:444-447

13. Mladenow A, Bauer C, Strauss C (2016) 'Crowd logistics': the contribution of social crowds in logistics activities. Int J Web Inform Syst 12:379-396

14. Huang LJ, Xie GJ, Blenkinsopp J, Huang RY, Bin H (2020) Crowdsourcing for sustainable urban logistics: exploring the factors influencing crowd workers' participative behavior. Sustainability 12(8): $1-20$

15. Ishfaq R, Sox CR (2011) Hub location-allocation in intermodal logistic networks. Eur J Oper Res 210(2):213-230

16. Hsiao CY, Hansen M (2011) A passenger demand model for air transportation in a hub-and-spoke network. Transport Res E-Log 47(6):1112-1125

17. Hsu CL, Wang CC (2013) Reliability analysis of network design for a hub-and-spoke air cargo network. Int J Log Res Appl 16(4):257-276

18. Yu N, Xu W, Yu KL (2020) Research on regional logistics demand forecast based on improved support vector machine: a case study of Qingdao city under the New Free Trade Zone Strategy. IEEE Access 8:9551-9564

19. Delfmann W, Albers S, Gehrin M (2002) The impact of electronic commerce on logistics service providers. Int J Phys Distrib Log Manage 32(3-4):203-223

20. He YP, Han HW, Zhang XY (2004) Modern logistics and e-commerce. Jinan University Press, Guangzhou, pp 56-58

21. Sink HL, Langley CJ (1997) A managerial framework for the acquisition of third-party logistics services. J Bus Log 18(2):163-189

22. Qian H (2019) E-commerce logistics mode selection based on network construction. Mod Econ 10(1):198-208

23. Ranard BL, Ha YP, Meisel ZF, Asch DA, Hill SS, Becker LB, Merchant RM (2014) Crowdsourcing-harnessing the masses to advance health and medicine, a systematic review. J Gen Intern Med 29(1):187-203

24. Bask A, Lipponen M, Tinnilä M (2012) E-commerce logistics: a literature research review and topics for future research. Int $\mathrm{J}$ E-ServMob Appl 4(3):1-22

25. Weltevreden JWJ (2008) B2c e-commerce logistics: the rise of collection-and-delivery points in The Netherlands. Int J Retail Distrib Manage 36(8):638-660

26. Nguyen TY (2020) Research on logistics demand forecast in southeast Asia. World J Eng Techn 8:249-256

27. Fan SX, Wu B (2018) Prediction analysis for logistics demand based on multiple kernels. Ind Eng Manage 23(02):40-44

28. Han HJ, Han JB, Zhang R (2019) Study on logistics demand forecasting model based on fuzzy cognitive map. Syst Eng-Th Pract 39(06):1487-1495
29. Du BC, Chen AL (2019) Research on logistics demand forecast based on the combination of grey GM $(1,1)$ and BP neural network. J Phys Conf Ser 2019:1288

30. Wang XP, Yan F (2018) Forecast of cold chain logistics demand for agricultural products in Beijing based on neural network. Guangdong Agr Sci 45(6):120-128

31. Yan P, Zhang L, Feng Z et al (2019) Research on logistics demand forecast of port based on combined model. J Phys: Conf Ser 2019:1168

32. Cao ZQ, Yang Z, Liu F (2018) Logistics volume forecast model of support vector regression optimized by genetic algorithm. J Syst Sci 26(4):79-82

33. Sadeghi BHM (2000) A BP-neural network predictor model for plastic injection molding process. J Mater Process Technol 103(3):411-416

34. Spearman C (1934) The factor theory and its troubles. V. Adequacy of proof. J Educ Psychol 25(4):310-319

35. Wu S, Pan FM (2014) SPSS statistical analysis. Tsinghua University Press, Beijing, pp 339-341

36. Deng JL (1982) Control problems of grey systems. Syst Contr Lett 1(5):288-294

37. Liu X, Peng H, Bai $Y$ et al (2014) Tourism flows prediction based on an improved grey GM $(1,1)$ model. Procedia-Soc Behav Sci 138(14):767-775

38. Shen X, Lu Z (2014) The application of grey theory model in the predication of Jiangsu province's electric power demand. AASRI Procedia 7:81-87

39. Chia N, Wang NT et al (2015) A study of the strategic alliance for EMS industry: the application of a hybrid DEA and GM (1, 1) approach. Sci World J 2015:1-15

40. Rumelhart DE, Hinton GE, Williams RJ (1986) Learning representations by back-propagating errors. Nature 323(6088):533-536

41. Saric T, Simunovic G, Vukelic D, Simunovic K, Lujic R (2018) Estimation of CNC grinding process parameters using different neural networks. Teh Vjesn 25(6):1770-1775

42. Chen M (2013) MATLAB neural network principles and examples of fine solution. Tsinghua University Press, Beijing, pp 156-158

43. Qin LL, Yu NW, Zhao DH (2018) Applying the convolutional neural network deep learning technology to behavioural recognition in intelligent video. Teh Vjesn 25(2):528-535

44. Zhang Z, Guan ZL, Zhang J, Xie X (2019) A novel job-shop scheduling strategy based on particle swarm optimization and neural network. Int J Simul Model 18(4):699-707

45. Hu W (2019) An improved flower pollination algorithm for optimization of intelligent logistics distribution center. Adv Prod Eng Manag 14(2):177-188

46. Nuzzolo A, Comi A, Rosati L (2014) City logistics long-term planning: simulation of shopping mobility and goods restocking and related support systems. Int J Urban Sci 18:201-217

47. Chen J, Zhong L, Anthony L (2018) Research on monitoring platform of agricultural product circulation efficiency supported by cloud computing. Wirel Pers Commun 102(4):3573-3587

48. Lyu G, Chen L, Huo B (2019) Logistics resources, capabilities and operational performance: a contingency and configuration approach. Ind Manage Data Syst 119(2):230-250

49. David F (2017) Redressing grievances with the treatment of dimensionless quantities in SI. Measurement 109:105-110

50. Afify HM, Mohammed KK, Hassanien AE (2020) Multi-images recognition of breast cancer histopathological via probabilistic neural network approach. J Syst Manag Sci 1(2):53-68

51. Lilien DM (2000) Econometric software reliability and nonlinear estimation in EViews: comment. J Appl Econom 15(1):107-110

52. Coyle EJ, Lin JH (1988) Stack filters and the mean absolute error criterion. IEEE Trans Acoust Speech Sign Proces 36(8):1244-1254 
53. Norman L (1946) The Wiener (root mean square) error criterion in filter design and prediction. J Math Phys 25(1-4):261-278

54. Khair U et al (2017) Forecasting error calculation with mean absolute deviation and mean absolute percentage error. J Phys Conf Ser 930:012002

55. Wang YF, Shi Y, Chen LH (2020) Third-party inventory forecasting application research of apparel supply chain based on BP neural network and grey GM $(1,1)$ model. Math Pract Theory 50(03):277-285

Publisher's Note Springer Nature remains neutral with regard to jurisdictional claims in published maps and institutional affiliations. 